\title{
Endovascular and Percutaneous Treatment of Pediatric Portosystemic Varices: A Case Review
}

\author{
Alexander Dabrowiecki, MD ${ }^{1}$ \\ C. Matthew Hawkins, MD ${ }^{1,4}$ \\ ${ }^{1}$ Department of Radiology and Imaging Sciences, Emory University \\ School of Medicine, Atlanta, Georgia \\ Eric J. Monroe, $\mathrm{MD}^{2}$ \\ 2 Department of Interventional Radiology, Seattle Children's Hospital, \\ Seattle, Washington \\ ${ }^{3}$ Department of Pediatrics, Division of Gastroenterology, \\ Hepatology, and Nutrition, Children's Pediatric Institute, Children's \\ Healthcare of Atlanta and Emory University, Atlanta, Georgia \\ ${ }^{4}$ Division of Interventional Radiology and Image Guided Medicine, \\ Children's Pediatric Institute, Children's Healthcare of Atlanta and \\ Emory University, Atlanta, Georgia
}

Rene Romero, $\mathrm{MD}^{3}$

Anne E. Gill, $\mathrm{MD}^{1,4}$

Address for correspondence Alexander Dabrowiecki, MD, 1364

Clifton Rd. NE, Suite \#D112, Atlanta, GA 30322

(e-mail: adabrow@emory.edu).

Dig Dis Interv 2019;3:214-226.

\author{
Abstract \\ Keywords \\ - portosystemic varices \\ - ectopic varices \\ - venous intervention \\ - pediatric \\ interventions
}

Portal hypertension is a significant cause of morbidity and mortality in pediatric patients. Complications of portal hypertension include development of portosystemic varices. The most common type of portosystemic varices are gastroesophageal varices; however, other ectopic varices can also be a cause of recurrent, life-threatening gastrointestinal bleeding. Problematic ectopic varices include isolated gastric, anorectal, small bowel, roux-limb, and stomal varices. There are no standardized treatment guidelines on how to manage ectopic varices in children; however, new innovations in endovascular treatment options provide potential therapeutic alternatives when varices are refractory to conventional therapy. This review provides a case-based literature review for endovascular treatment of isolated gastric, anorectal, small bowel, roux-limb, and stomal ectopic varices in children (age 0-9 years) and adolescents (age 10-19 years).

Portal hypertension in children is a significant cause of morbidity and mortality. One common complication associated with portal hypertension is the development of portosystemic varices, such as gastroesophageal and other ectopic varices (EcV). Portal hypertension in adults is defined as a hepatic venous pressure gradient greater than $5 \mathrm{~mm} \mathrm{Hg}$, and variceal formation occurs from a hepatic venous pressure gradient $\geq 10 \mathrm{~mm} \mathrm{Hg}$ leading to venous collateralization, classically in predictable locations. ${ }^{1}$ The most common type of varices are esophageal and gastroesophageal varices. However, less-common, yet equally as problematic, EcV include isolated gastric, anorectal, small bowel (most commonly duodenal), roux-limb, and stomal varices (-Figs. 1 and 2). Acute life-threatening variceal bleeding is the most

received

April 10, 2019 accepted after revision

June 6, 2019

published online

August 27, 2019 feared complication of all types of EcV. Traditionally, in children, most EcV have been treated both endoscopically and surgically. However, minimally invasive percutaneous and endovascular therapies have evolved as potential therapeutic options to treat $\mathrm{EcV}$ not amenable to endoscopic or surgical treatment in children. Transjugular intrahepatic portosystemic shunt (TIPS) creation has been extensively described in the peer-review literature to treat pediatric esophageal and gastroesophageal varices, ${ }^{2-5}$ and will, thus, not be extensively reviewed herein. This review, rather, focuses on the literature to date in a case-based and location-based approach to percutaneous and/or endovascular treatment of pediatric isolated gastric, anorectal, small bowel, roux-limb, and stomal EcV.
Copyright $\odot 2019$ by Thieme Medical Publishers, Inc., 333 Seventh Avenue, New York, NY 10001, USA. Tel: +1(212) 584-4662.
DOI https://doi.org/ 10.1055/s-0039-1694978. ISSN 2472-8721.
Interventions; Eric J. Monroe, MD 


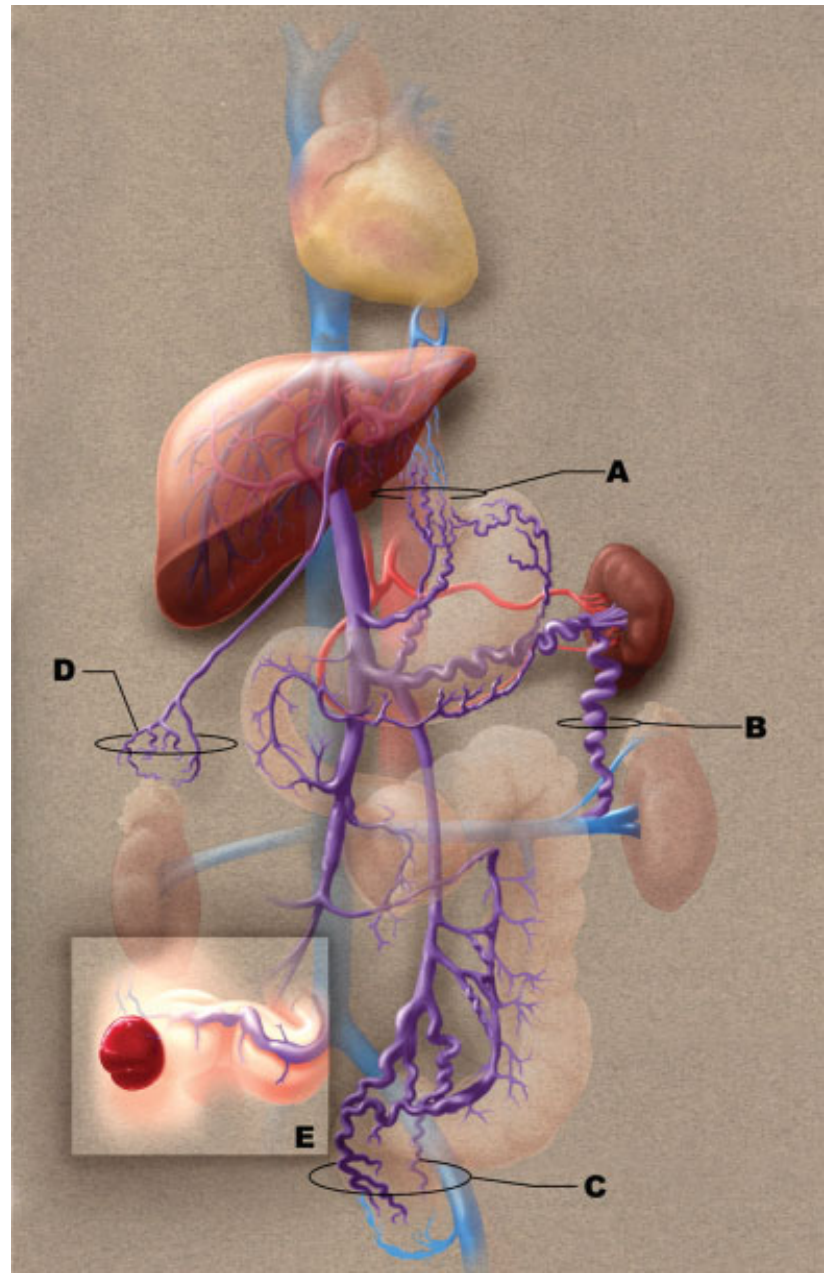

Fig. 1 Drawing illustrates the common portosystemic venous collateral pathways: the left gastric (coronary) and azygos veins at the lower esophagus (a); the splenic and left renal-adrenal veins at the spleen (b); the superior rectal and middle-inferior rectal veins at the anal canal (c); the veins of the ligamentum teres and the superior-inferior epigastric veins at the umbilicus (d); and the colonic-mesenteric veins, body wall veins, and IVC in the retroperitoneum (e). (Referenced from Glen Oomen, MSc, McMaster University, Dundas, Ontario, Canada.)

The pediatric literature is limited in its description of the risk factors for developing $\mathrm{EcV}$, as invasive hemodynamic measures are rarely performed and thus inferences are made from the adult literature including using similar hepatic vein pressure gradient thresholds as adults. ${ }^{6}$ In adults, there is a direct correlation between the degree of hepatic cirrhosis measured by Child Pugh or Model for End-Stage Liver Disease (MELD) scores and degree of hyperdynamic circulation and portal pressure gradient. ${ }^{7}$ Up to $60 \%$ of patients with decompensated cirrhosis (as evidenced by coagulopathy, ascites, and hepatic encephalopathy) and up to $30 \%$ of patients with compensated cirrhosis have varices. Approximately $10 \%$ to $20 \%$ of these patients' varices increase in size within 1 to 2 years. Importantly, size of esophageal varices is directly correlated with risk of variceal bleeding ${ }^{8}$ and variceal size is directly related to the degree of hepatic vein wedge pressure gradient elevation. Significant acute variceal bleeding is associated with up to $50 \%$ mortality $^{9}$ in adults, and, therefore, close attention to patients with $\mathrm{EcV}$ is necessary.

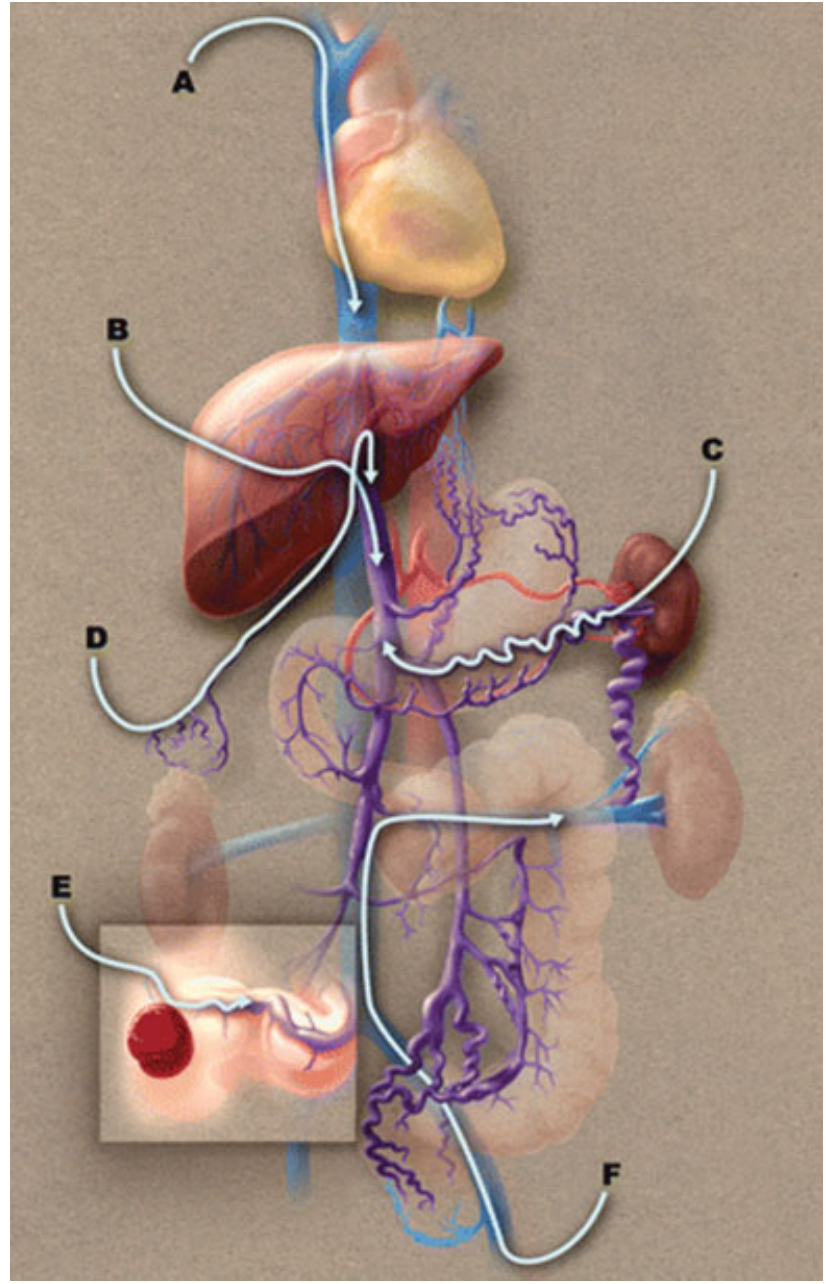

Fig. 2 Drawing illustrates the various routes that can be used to access the portal venous system in complicated portal hypertension, including transjugular (a), transhepatic (b), trans-splenic (c), transumbilical (d), transvariceal (stomal) (e), and transfemoral (systemicportal) (f) routes. (Referenced from Glen Oomen, MSc, McMaster University, Dundas, Ontario, Canada. ${ }^{94}$ )

However, more recent literature demonstrates pediatric mortality from variceal bleeding is uncommon, ${ }^{10}$ although long-term morbidity in these patients is not well described. ${ }^{6}$ Often times, gastrointestinal bleeding from a ruptured varix is the most common presenting symptom of portal hypertension. Life-threatening bleeding and complications occur mainly in patients with portal hypertension secondary to hepatic cirrhosis due to the downstream complications of hepatic decompensation.

\section{Pediatric Etiologies}

There are fundamental differences in the pathophysiology resulting in portal hypertension and subsequent $\mathrm{EcV}$ in pediatric patients when compared to adults. There are many different causes of pediatric portal hypertension, which can further be subdivided into extrahepatic (prehepatic and infrahepatic), intrahepatic, and post hepatic (-Table 1). 
Table 1 Causes of pediatric portal hypertension $91-93$

\begin{tabular}{|c|c|c|}
\hline \multirow[t]{3}{*}{ Intrahepatic } & $\begin{array}{l}\text { Biliary } \\
\text { disease }\end{array}$ & $\begin{array}{l}\text { Biliary atresia } \\
\text { Progressive familial intrahepatic } \\
\text { cholestasis } \\
\text { Primary sclerosing cholangitis } \\
\text { Cystic fibrosis } \\
\text { Intestinal failure-associated } \\
\text { liver disease }\end{array}$ \\
\hline & $\begin{array}{l}\text { Hepatic } \\
\text { disease }\end{array}$ & $\begin{array}{l}\text { Autoimmune hepatitis } \\
\text { Chronic viral hepatitis B/C } \\
\text { Alpha }_{1} \text {-Antitrypsin deficiency } \\
\text { Nonalcoholic fatty liver disease } \\
\text { Wilson's disease } \\
\text { Glycogen storage disease }\end{array}$ \\
\hline & $\begin{array}{l}\text { Fibrotic } \\
\text { disease }\end{array}$ & $\begin{array}{l}\text { Congenital hepatic fibrosis } \\
\text { Caroli disease }\end{array}$ \\
\hline \multirow[t]{5}{*}{ Prehepatic } & $\begin{array}{l}\text { Portal vein } \\
\text { occlusion }\end{array}$ & $\begin{array}{l}\text { Portal vein thrombosis } \\
\text { Tumor infiltration or } \\
\text { compression } \\
\text { Congenital atresia/agenesis }\end{array}$ \\
\hline & $\begin{array}{l}\text { Splenic vein } \\
\text { thrombosis }\end{array}$ & \\
\hline & $\begin{array}{l}\text { Increased } \\
\text { portal flow }\end{array}$ & Arteriovenous fistula \\
\hline & $\begin{array}{l}\text { Nodular } \\
\text { regenerative }\end{array}$ & $\begin{array}{l}\text { Drug therapy } \\
\text { (6-thioguanine and } \\
\text { azathioprine) } \\
\text { Turner syndrome }\end{array}$ \\
\hline & $\begin{array}{l}\text { Portal } \\
\text { stenosis }\end{array}$ & $\begin{array}{l}\text { Schistosomiasis } \\
\text { Idiopathic cause } \\
\text { HIV infection } \\
\text { Cystic fibrosis liver disease }\end{array}$ \\
\hline \multirow[t]{2}{*}{ Posthepatic } & $\begin{array}{l}\text { Hepatic vein } \\
\text { obstruction }\end{array}$ & $\begin{array}{l}\text { Budd-Chiari syndrome } \\
\text { Inferior vena cava obstruction } \\
\text { Congestive heart failure } \\
\text { Veno-occlusive disease } \\
\text { (sinusoidal obstruction) }\end{array}$ \\
\hline & $\begin{array}{l}\text { Cardiac } \\
\text { disease }\end{array}$ & $\begin{array}{l}\text { Right-sided heart failure } \\
\text { Cardiac tamponade }\end{array}$ \\
\hline
\end{tabular}

Although portal hypertension is mainly secondary to hepatic cirrhosis in adults, the two most common causes of portal hypertension in children are cirrhosis, with biliary atresia as the leading cause in developed countries ${ }^{11}$ and extrahepatic portal vein occlusion in developing countries and second most common cause of portal hypertension in developed countries. ${ }^{12-14}$ The discrepancy between developed and developing countries is not entirely clear, but the recorded prevalence of hepatitis B virus and Wilson's disease is higher in similar cohorts in developing countries which suggests underdiagnosis and/or undertreatment of these two conditions. ${ }^{11,12}$ In children who have received a liver transplant, studies have demonstrated portal venous thrombosis and stenosis rates of $3.7 \%$ to $50 \%$ in pediatric patients, irrespective of the reason for liver transplant, ${ }^{15-17}$ which can form new $\mathrm{EcV}$ or worsen existing EcV. Interestingly, posttransplantation portal venous thrombosis or stenosis is independently associated with increased mortality. ${ }^{17}$

Serial endoscopy for surveillance of gastroesophageal varices is discouraged in children, and noninvasive, highly accurate clinical prediction rules have been created based on spleen size, hypoalbuminemia, and platelet count to predict risk of forming esophageal varices. ${ }^{11,18}$ However, no such prediction rules have been delineated for the less common types of $\mathrm{ECV}$ discussed in this review likely due to the lack of published treatment and outcomes data .

\section{Baveno Consensus Recommendations: Prophylaxis versus Acute Variceal Bleeding}

Beginning in 1990, in response to the scarce literature on approaches to management of pediatric variceal bleeding, an expert panel has convened every 5 years in Baveno, Italy, to explore the data in pediatric variceal bleeding. The most recent consortium of the "Controversies in the Management of Varices in Children-An International Forum" met in 2015, and from this meeting, experts recommend no specific primary prophylaxis with either medication (nonselective beta-blockers), endoscopic variceal ligation, or sclerotherapy based on the lack of evidence. Meso-Rex Bypass (a vascular graft between the superior mesenteric vein and left portal vein) may be beneficial for primary and secondary prophylaxis in certain cases of extrahepatic portal vein occlusion. ${ }^{19}$ Endoscopic ligation and sclerotherapy can be performed to achieve hemostasis in gastroesophageal varices. In addition, for acute variceal bleeding, octreotide has been shown to be safe and effective in the majority of cases. ${ }^{20}$

Within the newest 2015 Baveno recommendations, endovascular therapy, specifically TIPS, was not directly addressed. However, the recommendations from the 2010 Baveno forum suggested that early TIPS placement (within 72 hours, ideally 24 hours) can be considered in the setting of chronic liver disease in patients with bleeding EcV that have failed initial pharmacological and endoscopic therapy. ${ }^{21}$

\section{Endovascular Therapy for Different Types of Ectopic Varices}

\section{Gastroesophageal Varices}

Gastroesophageal varices are the most common types of varices that occur in patients with portal hypertension. Although prevalence rates are not well defined in the pediatric literature, in adults, approximately $50 \%$ of patients with cirrhosis develop gastroesophageal varices and these varices are present in $5 \%$ to $33 \%$ of patients with portal hypertension. The rates of developing varices is approximately $5 \%$ to $8 \%$ annually with $1 \%$ to $2 \%$ of patients developing large enough varices placing them at risk for bleeding. ${ }^{22}$ Gastroesophageal varices have four classifications: gastroesophageal varices (GOV) 1 and 2 and isolated gastric varices (IGV) 1 and 2 (-Fig. 3). Importantly, recent literature suggests that TIPS is insufficient in treating isolated gastric varices with gastric variceal post-TIPS patency of $65 \%$, and recurrent bleeding rates of $27 \%,{ }^{23}$ suggesting more extensive occlusion of these varices is required for improved outcomes.

TIPS been researched extensively for decades in adults and is a safe and efficacious treatment option for gastroesophageal varices. ${ }^{24}$ More recently, retrospective reviews demonstrate 


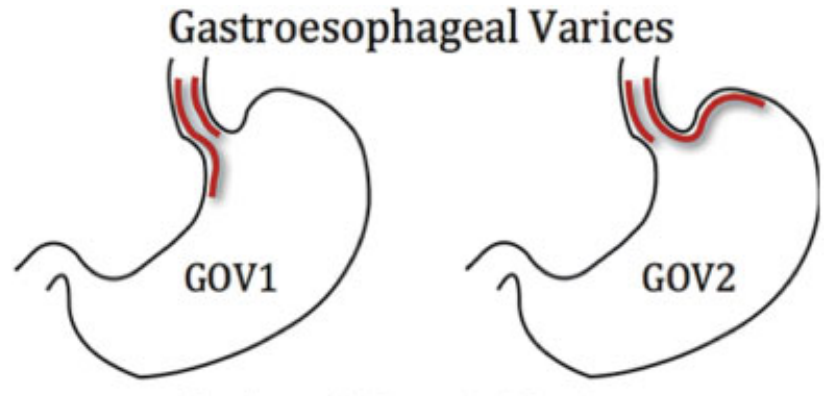

Isolated Gastric Varices
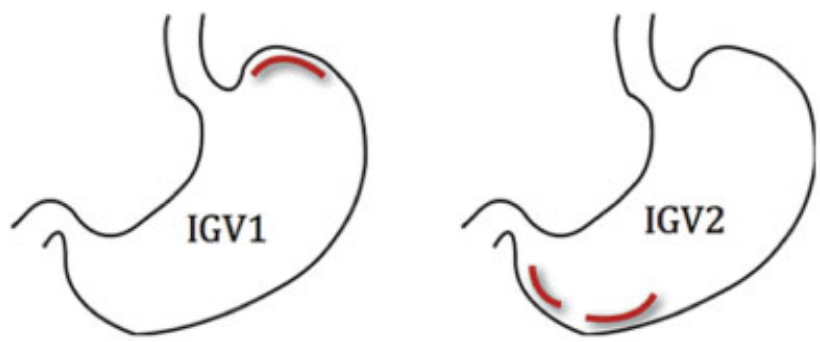

Fig. 3 Types of gastroesophageal (GOV) and isolated gastric varices (IGV). (Adapted from Sarin et al. ${ }^{95}$ )

TIPS shunts placed in pediatric patients demonstrated efficacy and safety comparable to that published in adults. ${ }^{2,5}$ Furthermore, a thorough review of pediatric TIPS was recently published by Monroe et al in February 2018. ${ }^{3}$ Thus, despite TIPS being the most commonly performed endovascular procedure for treatment of bleeding esophageal and gastroesophageal varices in children, the technical specifics of TIPS placement will not be discussed further in this manuscript.

\section{Isolated Gastric Varices}

Balloon-occluded retrograde transvenous obliteration (BRTO) has emerged as a safe, and potentially efficacious, minimallyinvasive therapeutic option for treating isolated gastric varices in certain patients, particularly IGV2. BRTO was first described in adults in Japan in the early 1990s, and the first case reports of pediatric BRTO were described in the early 2000s. To date, case reports of pediatric BRTO have been published on pediatrics from 2 to 15 years of age. ${ }^{25-31}$ The most commonly described technique in the literature to access the bleeding gastric varix is through a patent portocaval shunt as gastric varices drain by a gastrosplenorenal (87\%) shunt or a gastricinferior phrenic (16\%) shunt. ${ }^{32}$ If the gastrosplenorenal shunt is large enough to facilitate a retrograde approach, BRTO may be an appropriate treatment ( $\mathbf{- F i g} \cdot \mathbf{4 a - c}$ ). Successful pediatric BRTO has been reported in gastric varices secondary to biliary atresia, extrahepatic portal venous obstruction, and post-liver transplant portal hypertension ${ }^{26,29,31,33}$ in addition to congenital portosystemic (superior mesenteric veininferior vena cava and splenorenal) shunts. ${ }^{27}$ Alternatively, a trans-splenic approach may be used to access the varices if no large, spontaneous portosystemic shunt has developed (-Fig. 5a-g). Ultimately, pediatric BRTO can be successful in reducing the size and tension of gastric varices.

More recent literature demonstrates an alternative method to improve filling of the gastric varices during BRTO with temporary balloon-occlusion of the splenic artery. ${ }^{34}$ Temporary occlusion of the splenic artery with a 5-F balloon reduces pressures in the vein draining the gastric varix which adequately fills the gastric varix with the sclerosing agent, resulting in improved varix obliteration. ${ }^{35}$

The most common sclerosing agent used in the Japanese literature is ethanolamine oleate (Oldamin, Aska Pharmaceutical, Tokyo, Japan). However, there is a risk of hemoglobinuremia-related acute renal failure secondary to hemolysis from ethanolamine oleate, ${ }^{36,37}$ and prophylactic haptoglobin (Benesis, Osaka, Japan) can be administered preoperatively $^{27,38}$ to reduce this risk. Since haptoglobin is not available in the United States, alternative sclerosing agents and embolics with a lower risk of hemolysis are typically used, such as sodium tetradecyl sulfate (STS) (Sotradecol, AngioDynamics, Inc., Queensbury, New York), polidocanol (Polidocasklerol, ZERIA Pharmaceutical, Tokyo, Japan), $n$-butyl-2-cyanoacrylate (NBCA, Trufill, Cordis Neurovascular), and 50\% glucose. ${ }^{39}$ A foam sclerosant can be created with air or carbon dioxide to increase the injected volume without increasing the dosage of sclerosant, ensuring adequate contact with the endothelial cells of the varix. Common combinations in the United States include 1 part ethiodized oil (Lipiodol, Ethiodol, Savage Laboratories, Melville, New York), 2 parts $3 \%$ Sotradecol, and 3 parts carbon dioxide, ${ }^{39}$ or air. At our institution, our pediatric maximum dosage of $3 \%$ STS is $20 \mathrm{~mL}$ $(0.5 \mathrm{~mL} / \mathrm{kg})$ and ethiodized oil is $0.25 \mathrm{~mL} / \mathrm{kg}$ for all sclerosant mixtures.

\section{BRTO Outcomes}

Overall, BRTO is a well tolerated procedure with up to $95.5 \%$ success rate in a sample of 154 adult patients with similar results in a much smaller cohort of published pediatric patients. $^{38}$ Causative portal hypertension, however, may be exacerbated by the loss of decompressive spontaneous shunts emphasizing the importance of patient selection prior to BRTO. The obliteration of the spontaneous hepatofugal shunts in these patients can increase portal hypertension, worsening esophageal varices and ascites. ${ }^{40}$ Esophageal varices worsening following BRTO has been recorded in $10 \%$ to $63 \%$ of patients, with more recent literature demonstrating longitudinal exacerbation of esophageal varices at $1,3,5$, and 7 years of $13 \%$, $20 \%, 27 \%$, and $35 \%$, respectively. Overall 5 -year survival rates after BRTO are $50 \%$ to $72 \%$ in the adult populations. ${ }^{38}$ In adults, immediate postoperative clinical complications include transient fever (33\%), chest or epigastric pain (56\%), hemoglobinuria (49\%), hypertension (35\%), nausea or vomiting (21\%), gastric ulcers (9\%), and hemorrhagic portal hypertensive gastropathy (2\%). Less common complications ( 7 to 10 days postoperatively) include: pleural effusion (12\%), and pulmonary infarction (2\%). ${ }^{41-43}$ Routine monitoring of laboratory values one day post-BRTO demonstrate significant increases in indirect bilirubin, aspartate aminotransferase, and lactate dehydrogenase, returning to normal pre-BRTO levels by day seven. ${ }^{42}$ Total bilirubin significantly increases one day postBRTO; however, can be elevated for upwards of 36 months post-BRTO particularly in the setting of a patent splenorenal or gastrorenal shunt. ${ }^{41,42}$ 

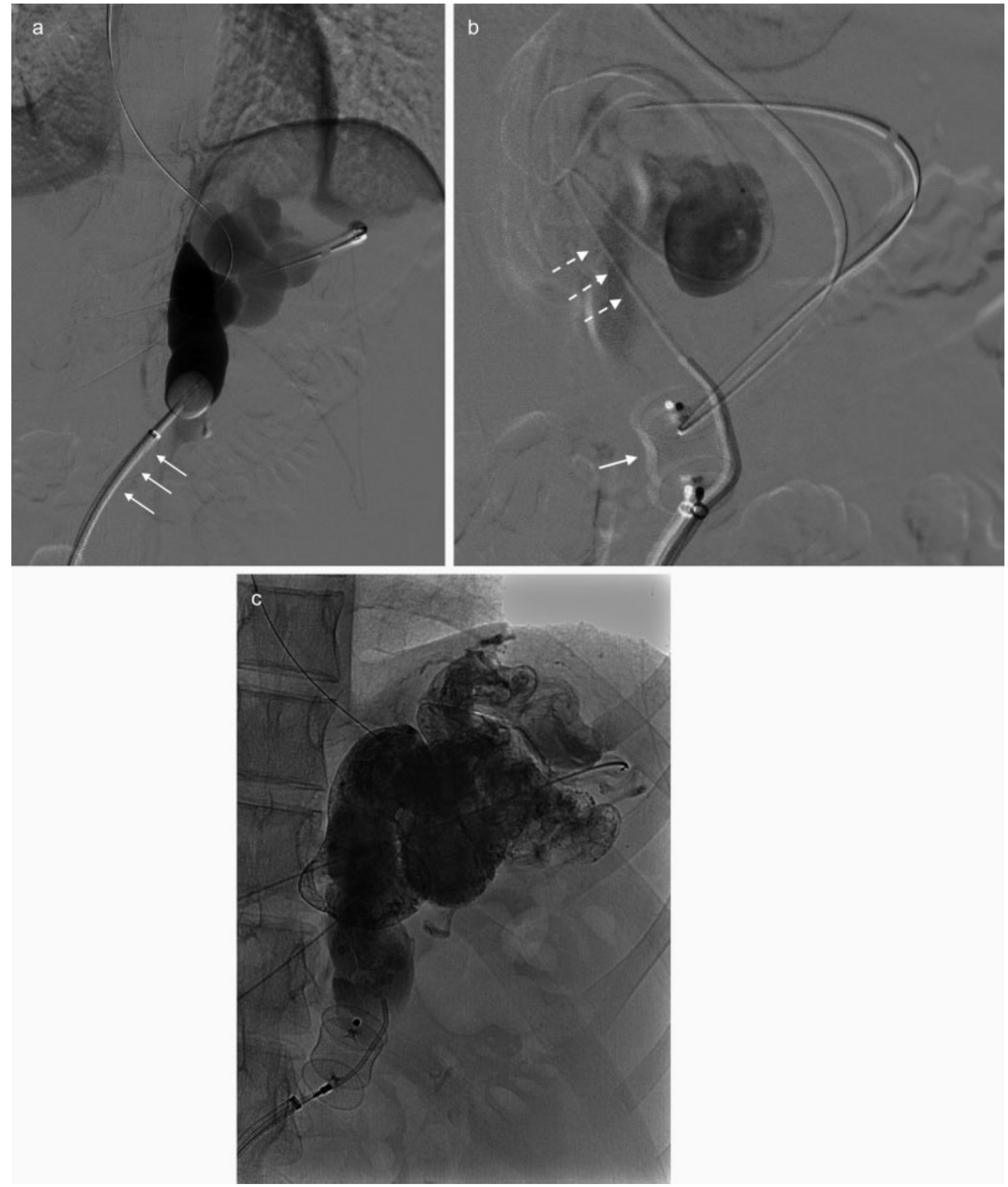

Fig. 4a-c A 16-year-old girl with biliary atresia status post Kasai hepatoportoenterostomy procedure with isolated gastric varices originally noted on endoscopy presented with severe hematemesis and a hemoglobin of $4 \mathrm{~g} / \mathrm{dL}$ and was nonresponsive to transfusions. - Figure 4 a shows opacification of large gastric varices following access into a gastrosplenorenal shunt from the right femoral vein and left renal vein with a 9F sheath (white arrows) and a 5F Python balloon-occlusion catheter ( $5 \mathrm{~F}$ is the maximum occlusion balloon size for pediatrics). Through the sheath, a 10mm AVP2 Amplatzer (St. Jude, Plymouth, Minnesota) occlusion device ( - Fig. 4b, white arrow) was deployed (but not detached). Alongside the occlusion device, a 4F angled catheter (Terumo, Somerset, New Jersey) (black arrow) was advanced, through which a 2.5F Cantata (Cook Medical Inc, Bloomington, Indiana) microcatheter (dashed white arrows) and 0.014 Synchro microwire (Stryker, Kalamazoo, Michigan) were used to obtain deep access into the gastric varices. $\mathbf{- F i g u r e} \mathbf{4 c}$ shows the distribution of 3\% Sotradecol (AngioDynamics, Inc., Queensbury, New York) embolic foam (3 parts air: 2 parts 3\% STS:1-part ethiodized oil, Guerbet, Princeton, New Jersey) throughout the varices. The AVP2 occlusion device was then deployed without egress of the embolic foam. The patient's bleeding and hematemesis ceased immediately. She received a transplant liver shortly thereafter. 


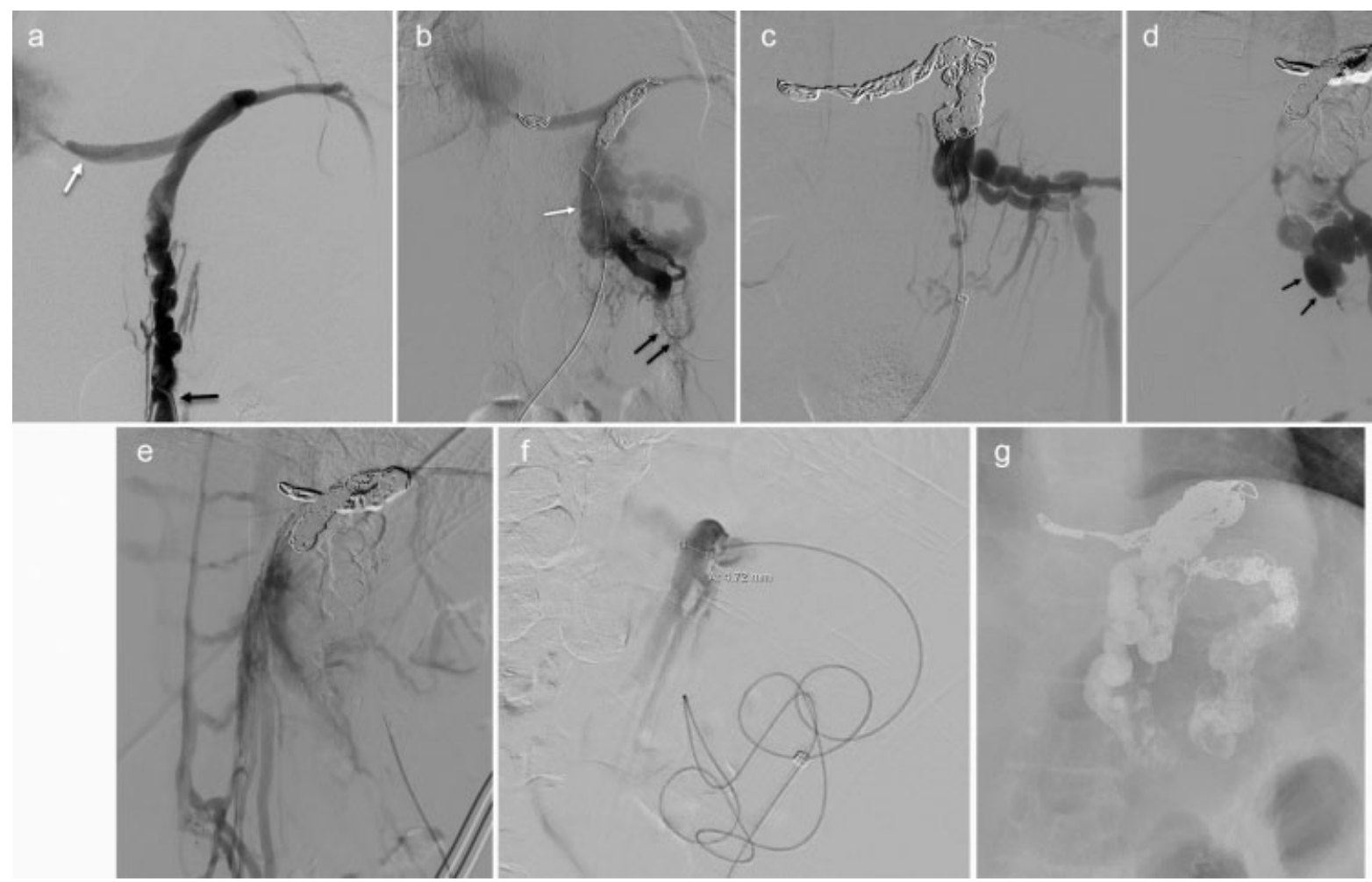

Fig. 5a-g An 18-year-old male with autoimmune hepatitis resulting in severe portal hypertension demonstrating large isolated gastric varices, anemia, and melena. Injection from a gastrorenal shunt (- Fig. 5a) shows opacification of a large inferior diaphragmatic vein without opacification of the gastric varices. Following partial embolization of the outflow veins, the gastric varices could still not be opacified from the gastrorenal shunt. As such, trans-splenic access was obtained ( $\mathbf{F i g} . \mathbf{5 b}$, black arrows) through which the gastric varices ( $\mathbf{- F i g}$. 5b, white arrow) were opacified with persistent outflow through the inferior diaphragmatic vein. Following complete embolization of the inferior diaphragmatic vein (-Fig. 5c) portions of the gastric varices were opacified from the gastrorenal shunt access site. Embolization with $3 \%$ Sotradecol (AngioDynamics, Inc., Queensbury, New York) embolic foam was performed in this portion of the gastric varices. Following initial Sotradecol foam (3 parts air:2 parts 3\% STS:1 part ethiodized oil, Guerbet, Princeton, New Jersey) embolization (- Fig. 5d) injection from the trans-splenic

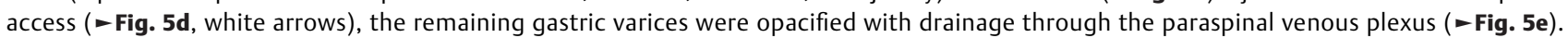
2.5F Cantata (Cook Medical Inc, Bloomington, Indiana) microcatheter and 0.014 Synchro (Stryker, Kalamazoo, Michigan) microwire were used to access the primary outflow into the paraspinal venous plexus (- Fig. 5f). Following coil embolization in this location, the remaining gastric varices were embolized (- Fig. $\mathbf{5 g}$ ). This patient's melena ceased immediately. He has since received a transplant liver.

\section{Anorectal Varices}

Anorectal varices form from a feeding superior rectal vein and drained by either a middle or inferior rectal vein. Anorectal varices are reported to occur in up to $35 \%$ of pediatric patients with portal hypertension from both intrahepatic and prehepatic causes. ${ }^{44}$ There is otherwise scant literature describing the epidemiology and prevalence of pediatric anorectal varices. In the authors' experience, the prevalence of anorectal varices is less than that reported in the literature. Based on available adult literature, there is an increased incidence of anorectal varices in patients with gastroesophagel varices. There is an additional increased incidence if a patients' gastroesophageal varices have previously hemorrhaged. ${ }^{45} \mathrm{Al}$ though anorectal varices are more common in adults, they have a low clinically significant bleeding rate from $0.5 \%$ to $5 \% .{ }^{46}$ Anorectal variceal gastrointestinal hemorrhage can be difficult to detect and treat. There are currently no guidelines in the adult or pediatric literature regarding management of bleeding anorectal varices.

There are a variety of approaches to managing anorectal variceal hemorrhage, however, one of the initial steps include vasoactive agents (terlipressin or octreotide) in com- bination with empiric antibiotic therapy. ${ }^{47}$ In the event that endoscopic ligation or sclerosis cannot be performed, endovascular therapy can be an alternative option. Although TIPS and BRTO have been successful in the pediatric literature for gastroesophageal varices as described above, there are many successful modified techniques for managing bleeding anorectal varices in the adult literature including TIPS, double balloon-occlusion embotherapy (DBOE), ${ }^{48}$ modified percutaneous transhepatic obliteration (MPTO), ${ }^{49}$ BRTO, ${ }^{50}$ balloon-occluded antegrade transvenous sclerotherapy (BATS), and balloon-occluded antegrade transvenous obliteration (BATO) $)^{51,52}$ (-Fig. 6a,b). There are no published pediatric cases of the other modified techniques described in the adult literature, but given their technical success, these are potential options for managing bleeding anorectal varices. In addition to the variable techniques once selecting the varix in question, there have been multiple different adult cases published on the approach to reach the varix of interest including transhepatic, paraumbilical, and transileocolic access (through a pararectal approach) which are potential routes to select the varix in pediatric patients given their high incidence of extrahepatic portal vein occlusion. ${ }^{49,53,54}$ 


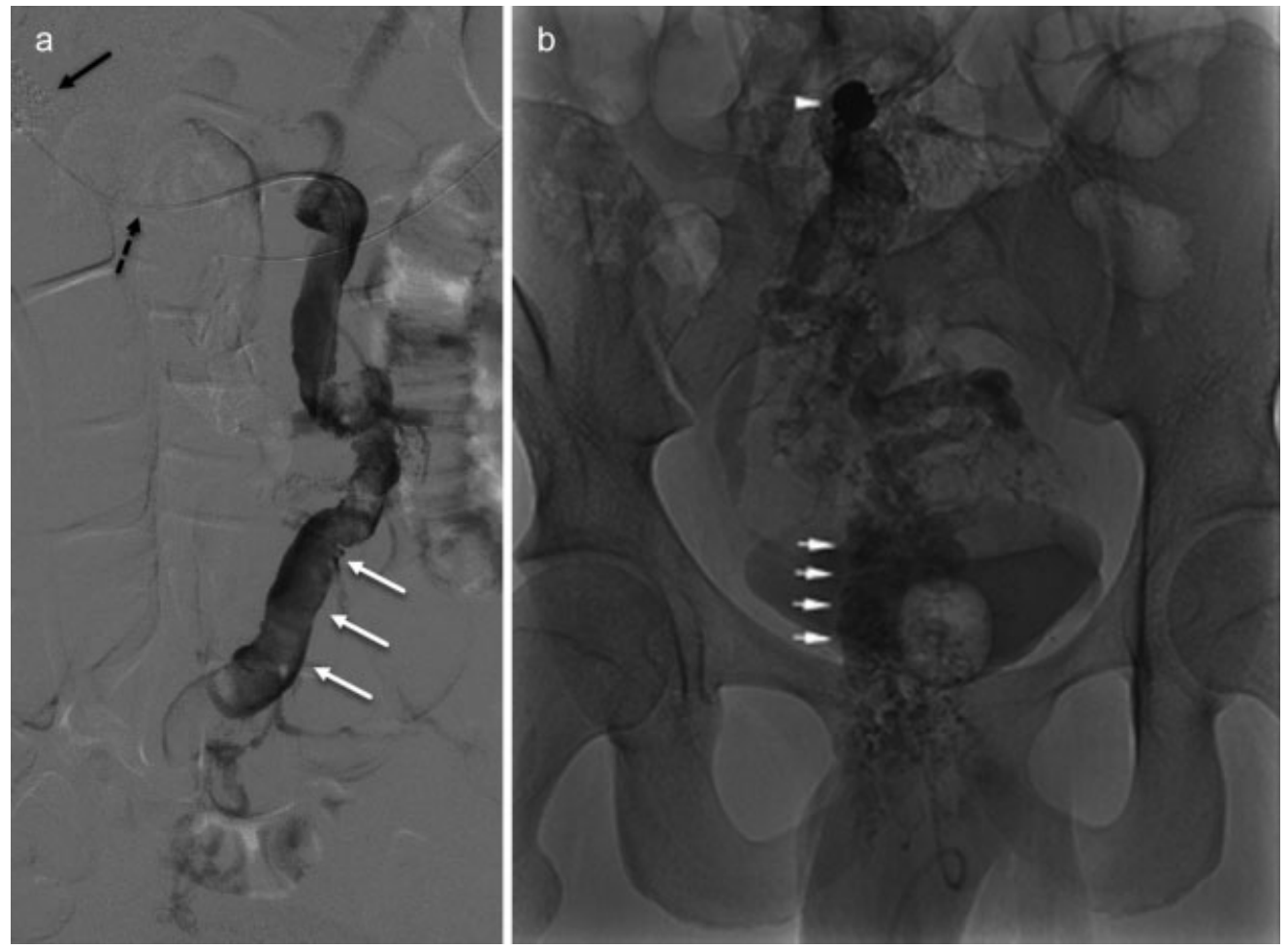

Fig. 6a,b A 17-year-old boy with idiopathic portal hypertension complicated by recurrent gastrointestinal bleeding secondary to rectal varices, presented with severe rectal bleeding following endoscopic biopsy. The patient's bleeding was complicated by concomitant portal vein thrombosis requiring TIPS creation ( - Fig. 6a, black arrow). At the time of the TIPS creation, embolization of the rectal varices was performed. Through the TIPS, a 4F catheter ( - Fig. 6a, dashed black arrow) was used to access a markedly enlarge inferior mesenteric vein ( Fig. 6a, white arrows). Through this access, a 5F Python

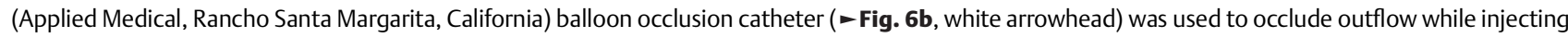
Sotradecol embolic foam (3 parts air:2 parts 3\% STS:1 part ethiodized oil, Guerbet, Princeton, New Jersey) which completely filled the rectal varices

( - Fig. 6b, white arrows). Multiple 0.035 coils were deployed through the occlusion balloon catheter to stop outflow of embolic foam. The patient's rectal bleeding ceased immediately. He has not had rectal bleeding since.

Embolic material is similar to that which can be used for gastric varices in BRTO as described above, and a single case report demonstrated success with a novel embolic and sclerosant mixture: $1 \mathrm{gm}$ of Avitene (Bard, Tempe, Arizona), $4 \mathrm{~mL}$ of 3\% Sotradecol (Angiodynamics, Latham, New York), and 1 $\mathrm{cm}^{3}$ of shredded Gelfoam (Pfizer, New York), mixed in $40 \mathrm{~mL}$ of nonionic contrast medium (Omnipaque 350; GE Healthcare, Marlborough, MA) followed by a Amplatzer plug 2 in the inferior mesenteric vein. ${ }^{55}$ Alternatively, embolization of reversed superior rectal venous tributaries, alone or in combination with TIPS, may be an effective temporizing measure. In all the adult cases, technical success was achieved without major complications; however, with any embolic deposition into the systemic venous circulation, there is a risk for nontarget embolization and pulmonary embolism. In the commonly used transhepatic approach, intraperitoneal hemorrhage has been reported to occur in up to $10.6 \%$ of adult patients. ${ }^{56}$

\section{Small Bowel and Roux Limb Varices}

Pediatric small bowel varices are less common than other EcVs in the setting of portal hypertension and are difficult to diagnose; however, they can cause morbidity and mortality secondary to chronic gastrointestinal bleeding and severe anemia. It may be seen in a slightly higher frequency in children who have biliary atresia and have undergone a hepatoportoenterostomy who then proceed with the development of portal hypertension. ${ }^{57}$ When endoscopic evaluation fails identify a source of upper or lower gastrointestinal bleeding, capsule endoscopy can aid in diagnosis and localization of ectopic small bowel varices for endovascular intervention. ${ }^{58}$ Additional diagnostic imaging considerations include a conventional $C T$ venous phase and percutaneous transhepatic portography. ${ }^{59}$ Often, endoscopic management is not possible due to distal location when medical management fails.

Duodenal varices account for $17 \%$ to $33 \%$ of ectopic $\mathrm{EcV},{ }^{60-62}$ and form as thin-walled retroperitoneal portoportal and/or portosystemic collaterals. The afferent feeding vessels include the pancreaticoduodenal, superior mesenteric, gastroduodenal, and pyloric veins while the draining vessels are typically the gonadal and capsular renal veins. ${ }^{63,64}$ Two-thirds of duodenal varices originate from intrahepatic portal hypertension, ${ }^{65}$ and although there is a relatively low prevalence of duodenal varices, there is a fourfold risk of bleeding when compared to esophageal varices. ${ }^{66}$ There is no standardization of how to manage bleeding duodenal varices, and there is a paucity of literature regarding management of bleeding pediatric duodenal varices. In the adult literature, there are case reports and small case series demonstrating the technical success of endovascular management through TIPS ( - Figs. 7a,b; 8a-c), BRTO, BATS, BATO, and improving portal venous patency. ${ }^{67,68}$ The rebleed 


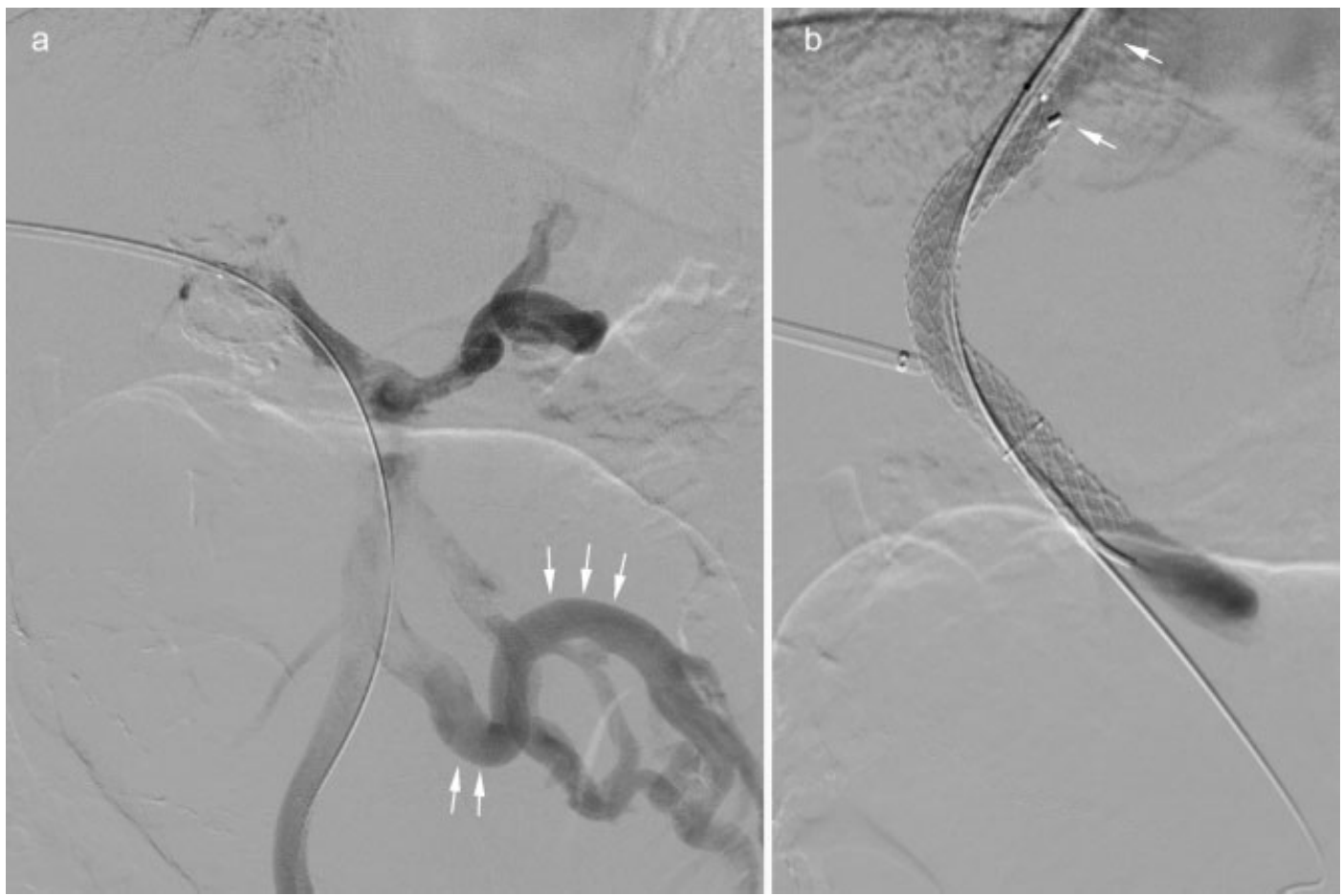

Fig. 7a,b A 16-year-old boy with cystic fibrosis, end-stage liver disease, and long-standing portal hypertension with recurrent gastrointestinal bleeding and anemia. Capsule endoscopy demonstrated small bowel varices. Transhepatic access demonstrates a large ectatic superior mesenteric varix ( - Fig. 7a, white arrows). TIPS was created with a $10 \mathrm{~mm} \times 8 \mathrm{~cm} \times 2 \mathrm{~cm}$ Viatorr (Gore, Flagstaff, Arizona) with subsequent cessation of gastrointestinal bleeding. Of note, the TIPS shunt was intentionally left short ( - Fig. $\mathbf{7 b}$, white arrows) so as not to interfere with future hepatic vein anastomosis in the setting of a liver transplant. Bleeding stopped following TIPS creation, and the patient received a liver transplant shortly thereafter.

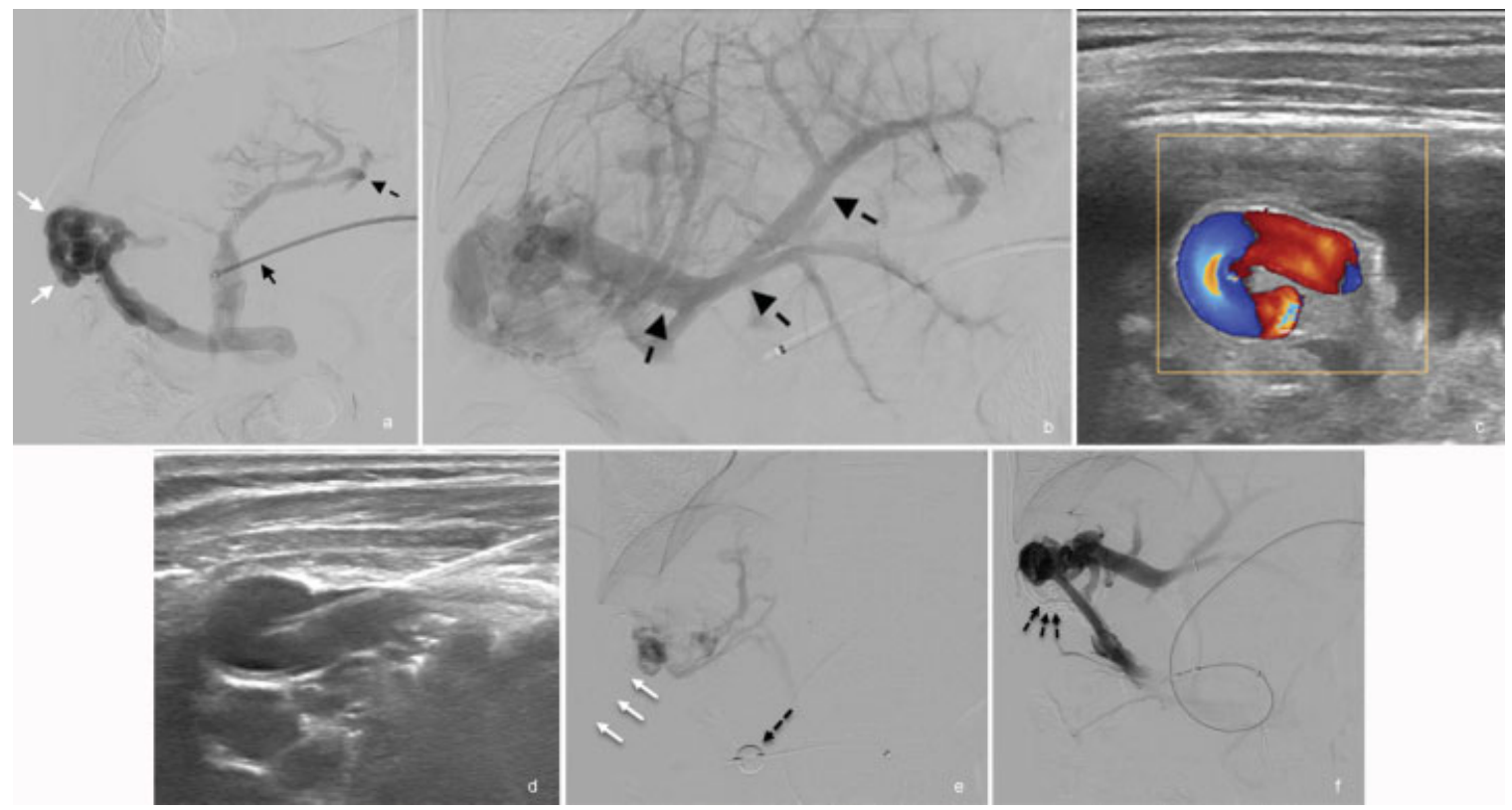

Fig. 8a-f A 14-year-old girl with cavernous transformation of the portal vein and severe gastrointestinal bleeding and anemia nonresponsive to transfusions many years after a left-lateral segment liver transplant for biliary atresia. Based on cross-sectional imaging, varices surrounding her roux-limb were suspected to be the source of bleeding. - Figure 8a shows an injection from trans-splenic access (black arrow) filling large roux-limb varices (white arrows), as well as mesenteric-to-portal collaterals (black dashed arrows). - Figure $\mathbf{8 b}$ shows a later phase following the same injection showing eventual opacification of the portal vein (dashed black arrows). Following multiple unsuccessful attempts to catheterize the roux-limb varices, ultrasound was used to identify the roux-limb varices ( - Fig. 8c). Direct access was obtained into the varices ( - Fig. 8d). — Figure 8e shows contrast injection into the roux-limb varices through the percutaneous access (white arrows). Note the occlusion balloon (dashed black arrow), which was inflated to eliminate the risk of reflux of embolic foam into the native portal vein. Following injection of Sotradecol embolic foam (3 parts air:2 parts 3\% STS:1-part ethiodized oil, Guerbet, Princeton, New Jersey) ( - Fig. 8f, black dashed arrows), there is more rapid opacification of the intrahepatic portal vein with no enhancement of the roux-limb varices. Her bleeding ceased immediately. 
rates of duodenal varices after TIPS is $21 \%$ to $37 \%$ and after transvenous obliteration is $13 \%{ }^{63}$ A five-patient case series by Saad et al demonstrated a combination of TIPS and transvenous obliteration to be successful in preventing postprocedural duodenal variceal hemorrhage up to a mean of 22 months (range 6-50 months). Based on the nature of the thin-walled duodenal varices, the same authors recommend transvenous obliteration over coil embolization (newer softer coils preferred), and caution in avoiding the submucosal and extraluminal components of the varix to ensure adequate obliteration. ${ }^{68}$ As with BRTO of the gastroesophageal varices, similar embolic agents have been used for obliterating duodenal varices including ethanolamine oleate, $3 \%$ sodium tetradecyl sulfate, $50 \%$ glucose, absolute etha- nol, ${ }^{68}$ and there are similar complications with BRTO as described above.

Jejunal varices can result in obscure bleeding and the prevalence is not well recorded in the literature. Only a single case of pediatric jejunal varix embolization has been reported, which was technically successful and in conjunction with trans-splenic portal vein recanalization and stenting after liver transplant. ${ }^{69}$ A study of trans-splenic endovascular intervention ( $\mathbf{- F i g}$. 9a-f) demonstrated success in treating eight patients with Roux limb varices; however, intraperitoneal bleeding occurred in $27 \%$ of patients with a significant correlation between hemorrhage and intraprocedural anticoagulation. ${ }^{70}$ The majority of published case reports and small case series of successful
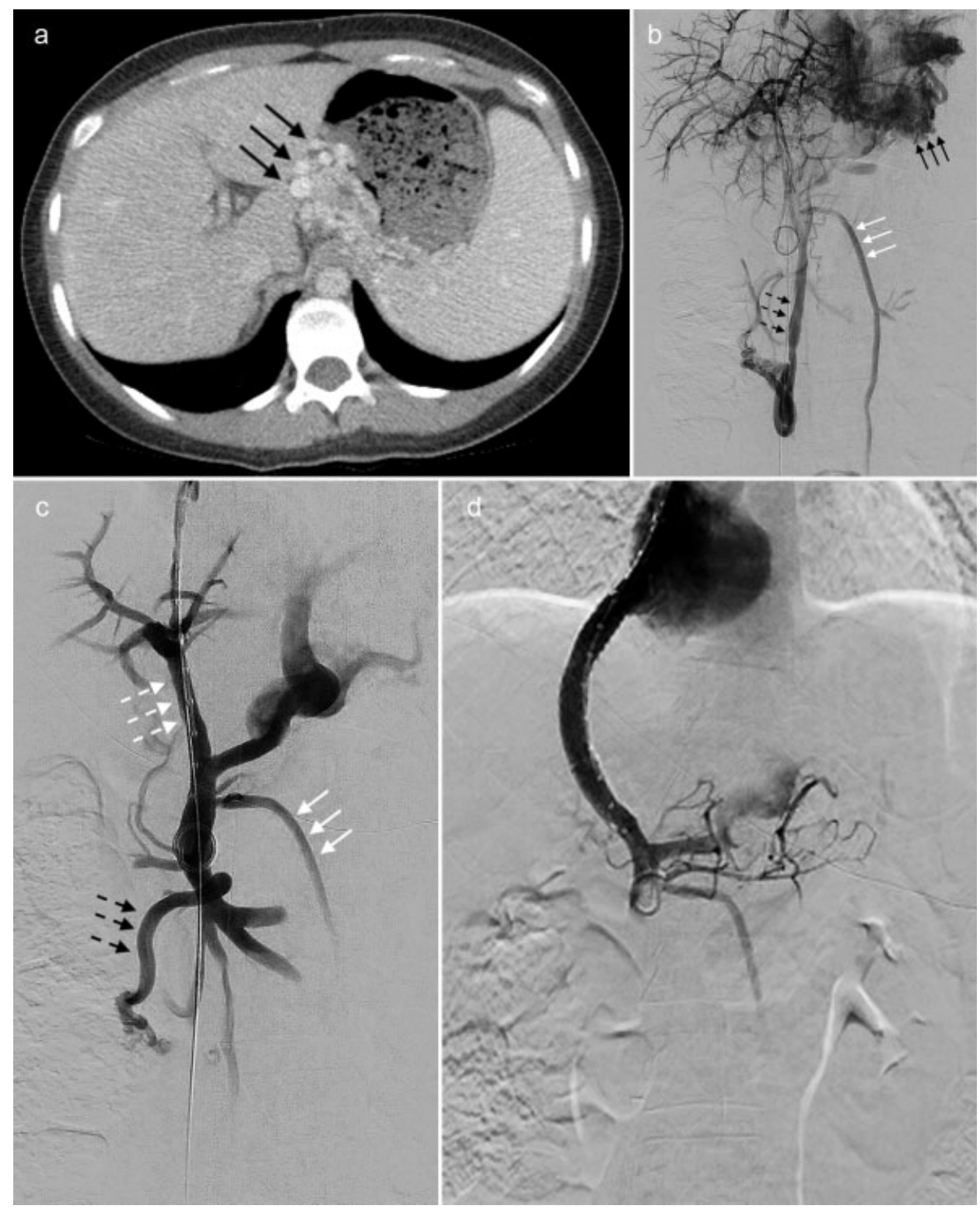

Fig. 9a-d An 18-year-old female with portal sclerosis presented with upper gastrointestinal bleeding secondary to spontaneous portosystemic collaterals. Axial portal venous phase CT image (- Fig. 9a) demonstrated extensive gastroesophageal varices (black arrows). Early (-Fig. 9b) and late (-Fig. 9c) portal venogram prior to TIPS placement demonstrated a small caliber main portal vein (white dashed arrows), reversed flow within the inferior mesenteric vein (white arrows), an enlarged coronary vein supplying extensive gastric and gastroesophageal varices (black arrows), and duodenal varices draining to the inferior vena cava with the right gonadal vein (black dashed arrows). Post-TIPS portal venogram demonstrates decreased filling of the collaterals (-Fig. 9d). 
management of bleeding jejunal varices in adults are in patients with prior liver transplant, extrahepatic portal venous obstruction, or hepatopancreatobiliary surgery (commonly choledocojejunostomy) which suggests an altered venous collateralization pathway postprocedurally leading to varices at the jejunal anastamosis. ${ }^{59,71-75}$ There are only three cases reported of adults patients with bleeding jejunal varices without portal hypertension or prior surgery, ${ }^{76}$ and none in the pediatric literature.

In the single published pediatric patient with a bleeding jejunal varix, a Gelfoam slurry (Pfizer, New York), was used to achieve hemostasis, ${ }^{69}$ while the adult literature expands on the treatment options with two main treatment options as direct jejunal variceal obliteration or portal vein decompression to improve hepatopetal flow, occasionally as sequential or combined procedures. ${ }^{73}$ Successful embolization of small bowel varices in adults has been achieved with anhydrous ethanol, NBCA (NBCA:ethiodized oil 1:1-1:6), interlocking coils, and/or microcoils. ${ }^{59,71-73,75}$

\section{Stomal Varices}

Stomal varices occur at the surgically created mucocutaneous anastomosis secondary to portosystemic collateralization after colonic or small bowel enterostomies. ${ }^{63}$ These types of varices have a higher association in patients with ulcerative colitis and primary sclerosing cholangitis. ${ }^{77}$ Stomal varices hemorrhage in up to $27 \%$ of patients and occur on average 2 years after stoma formation. Stomal variceal hemorrhage conveys a $3 \%$ to $4 \%$ mortality risk. ${ }^{78}$ Typically, the feeding vessels of stomal varices are the colic or ileal veins, and the inferior epigastric is the dominant draining vessel. ${ }^{75}$ Given their superficiality, stomal varices can be diagnosed with Doppler ultrasound and are commonly treated conservatively such as with direct pressure. For recurrent or lifethreatening bleeding, more invasive treatment may be required. However, as with other EcV, there are no standard guidelines for management and the two mainstays of endovascular therapy are portal decompression (TIPS, improving hepatopetal flow) or direct embolization. ${ }^{79}$ The pediatric literature is scarce in describing direct embolization techniques; however, small case series in the adult literature had successful obliteration with BRTO with NBCA:ethiodized oil (1:3-1:6), onyx, and coil embolization. Endovascular therapy (-Fig. 10a-e) has a high technical success rate with a low rebleeding rate in the multiple case studies in the adult literature. ${ }^{4,80-84}$

\section{Postprocedural Imaging}

Postoperative imaging follow-up has not been well described in the pediatric setting for less common EcV discussed in this review. The adult literature describes post-BRTO imaging recommendations to confirm obliteration of the varices. Given the lack of data for other adult EcV follow-up, the recommendations below can be an alternative option for postprocedural
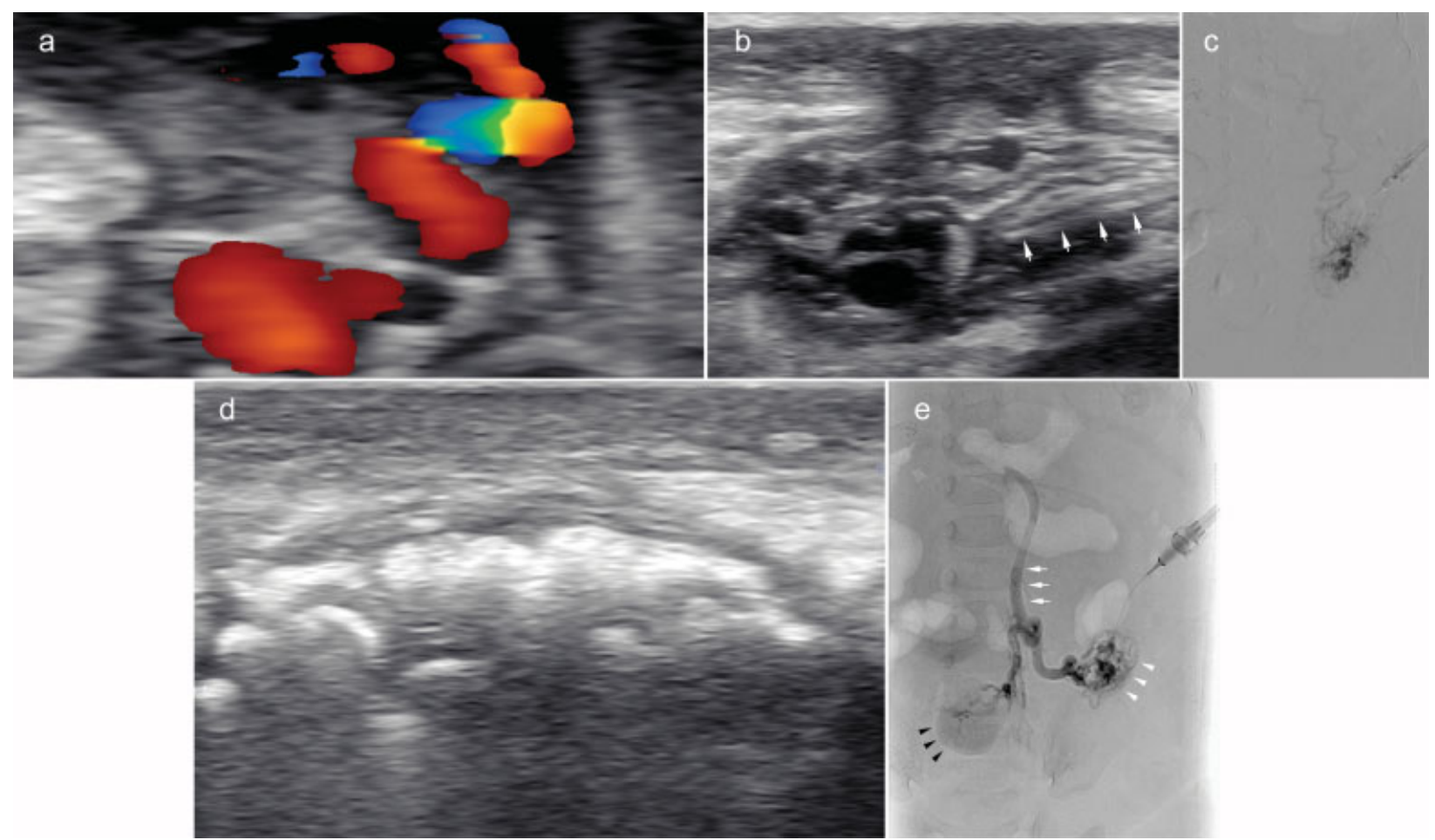

Fig. 10a-e A 7-month-old male child with biliary atresia and portal hypertension complicated by peristomal varices ( - Fig. 10a) an intractable hemorrhage. Direct access was obtained into the peristomal varices using a 22-guage angiocatheter ( - Fig. 10b). Initial contrast injection ( Fig. 10c) showed drainage from the ileostomy peristomal varices through a small collateral vessel. This outflow vein thrombosed quickly, redistributing embolic foam ( 3 parts air:2 parts 3\% STS:1-part ethiodized oil, Guerbet, Princeton, New Jersey) into the varices surrounding both the ileostomy and mucous fistula. - Figure 8d shows ultrasound appearance of the embolic foam. - Figure 10e shows distribution of embolic filling the varices around the ileostomy (white arrowheads), the varices near the mucous fistula (black arrowheads), as well as the inferior mesenteric vein. The patient had immediate cessation of bleeding and received a transplant a few weeks later. 
imaging for all types of treated EcV until tailored recommendations are further defined. Prior to discharge or within the first week, it is recommended to obtain contrast-enhanced cross-sectional imaging and/or endoscopic ultrasound imaging of the varices to ensure obliteration and assess for complications such as portal thrombus, retroperitoneal bleeding, and infection. ${ }^{85}$ Long-term follow-up is recommended with contrast-enhanced computed tomography (CECT) or contrastenhanced magnetic resonance imaging (CEMRI) at 1, 3, 6, and 12 months, then every 6 months or annually ${ }^{86,87}$ When ethiodized oil is used to aid in visualization of the foam forms of the sclerosant during angiography, follow-up with CEMRI may be considered secondary to ethiodized oil's hyperdense appearance on CECT. ${ }^{88}$ Endoscopic ultrasound may provide additional diagnostic value with the ability to characterize thrombosed or partially thrombosed gastroesophageal varices, predict risk of specific variceal bleeding, and identify collateral vasculature information for endoscopic treatment. However, current limitations include cost and availability of equipment and expertise at pediatric hospitals. ${ }^{89,90}$

\section{Conclusion}

Pediatric portal hypertension can lead to portosystemic collateralization in the form of gastroesophageal, isolated gastric, anorectal, small bowel, roux-limb, and stomal varices. These varices can result in morbidity and mortality secondary to acute and/or chronic bleeding that can be life threatening. Although TIPS for bleeding gastroesophageal varices has been the most well-studied endovascular or percutaneous therapy in the setting of $\mathrm{EcV}$, little literature is otherwise available to guide clinicians caring for patients with bleeding $\mathrm{EcV}$ in other locations. To date, the majority of the literature is derived from case reports and small case series to describe the management of these bleeding ectopic varices, and the literature demonstrates a lack of standardization in management. This review demonstrates that percutaneous endovascular therapeutic options can be safe and efficacious options to embolize ectopic varices in appropriately selected pediatric patients when medical and endoscopic therapy fail or are precluded.

\section{Conflict of Interest}

None.

\section{References}

1 Koh C, Heller T. Approach to the diagnosis of portal hypertension. Clin Liver Dis 2012;1(05):133-135

2 Bertino F, Hawkins CM, Shivaram G, et al. Technical feasibility and clinical effectiveness of transjugular intrahepatic portosystemic shunt creation in pediatric and adolescent patients. J Vasc Interv Radiol 2019;30(02):178-186.e5

3 Monroe EJ, Shin DS, Shivaram GM, Koo KSH. Pediatric transjugular intrahepatic portosystemic shunts. Dig Dis Interv 2017;01(04): 277-285

4 Maciel MJS, Pereira OI, Motta Leal Filho JM, et al. Peristomal variceal bleeding treated by coil embolization using a percutaneous transhepatic approach. World J Clin Cases 2016;4(01):25-29

5 Ghannam JS, Cline MR, Hage AN, et al. Technical success and outcomes in pediatric patients undergoing transjugular intra- hepatic portosystemic shunt placement: a 20-year experience. Pediatr Radiol 2019;49(01):128-135

6 Shneider BL, Bosch J, de Franchis R, et al; expert panel of the Children's Hospital of Pittsburgh of UPMC. Portal hypertension in children: expert pediatric opinion on the report of the Baveno $v$ Consensus Workshop on Methodology of Diagnosis and Therapy in Portal Hypertension. Pediatr Transplant 2012;16(05):426-437

7 Møller S, Hobolth L, Winkler C, Bendtsen F, Christensen E. Determinants of the hyperdynamic circulation and central hypovolaemia in cirrhosis. Gut 2011;60(09):1254-1259

8 Lebrec D, De Fleury P, Rueff B, Nahum H, Benhamou JP. Portal hypertension, size of esophageal varices, and risk of gastrointestinal bleeding in alcoholic cirrhosis. Gastroenterology 1980;79 (06):1139-1144

9 Carbonell N, Pauwels A, Serfaty L, Fourdan O, Lévy VG, Poupon R. Improved survival after variceal bleeding in patients with cirrhosis over the past two decades. Hepatology 2004;40(03):652-659

10 van Wessel DB, Witt M, Bax N, et al. Variceal bleeds in patients with biliary atresia. Eur J Pediatr Surg 2018;28(05):439-444

11 Fagundes EDT, Ferreira AR, Roquete MLV, et al. Clinical and laboratory predictors of esophageal varices in children and adolescents with portal hypertension syndrome. J Pediatr Gastroenterol Nutr 2008;46(02):178-183

12 Arora NK, Lodha R, Gulati S, et al. Portal hypertension in north Indian children. Indian J Pediatr 1998;65(04):585-591

13 Pariente D, Franchi-Abella S. Paediatric chronic liver diseases: how to investigate and follow up? Role of imaging in the diagnosis of fibrosis. Pediatr Radiol 2010;40(06):906-919

14 Poddar U, Thapa BR, Rao KL, Singh K. Etiological spectrum of esophageal varices due to portal hypertension in Indian children: is it different from the West? J Gastroenterol Hepatol 2008;23 (09):1354-1357

15 Millis JM, Seaman DS, Piper JB, et al. Portal vein thrombosis and stenosis in pediatric liver transplantation. Transplantation 1996; 62(06):748-754

16 Alvarez F. Portal vein complications after pediatric liver transplantation. Curr Gastroenterol Rep 2012;14(03):270-274

17 Waits SA, Wojcik BM, Cai S, Mathur AK, Englesbe MJ. Portal vein thrombosis and outcomes for pediatric liver transplant candidates and recipients in the United States. Liver Transpl 2011;17 (09):1066-1072

18 Gana JC, Turner D, Mieli-Vergani G, et al. A clinical prediction rule and platelet count predict esophageal varices in children. Gastroenterology 2011;141(06):2009-2016

19 Shneider BL, de Ville de Goyet J, Leung DH, et al. Primary prophylaxis of variceal bleeding in children and the role of MesoRex Bypass: summary of the Baveno VI Pediatric Satellite Symposium. Hepatology 2016;63(04):1368-1380

20 Corley DA, Cello JP, Adkisson W, Ko WF, Kerlikowske K. Octreotide for acute esophageal variceal bleeding: a meta-analysis. Gastroenterology 2001;120(04):946-954. Doi: 10.1053/gast.2001.22451

21 De Franchis R. Revising consensus in portal hypertension: report of the Baveno V Consensus Workshop on Methodology of Diagnosis and Therapy in Portal Hypertension. J Hepatol 2010;53(04): 762-768

22 Khan Sarin AW, Le Mair AS, Gangl A, Khan Bjorkman R, Eliakim R, Bektaeva SK, Sarin S, Fedail JH, Krabshuis AW, Le Mair AD. World Gastroenterology Organisation Global Guidelines Esophageal Varices; 2014http://www.spg.pt/wp-content/uploads/2015/11/ 2014-ESOPHAGEAL-VARICES.pdf. Accessed January 24, 2019

23 Lakhoo J, Bui JT, Lokken RP, Ray CE Jr, Gaba RC. Transjugular intrahepatic portosystemic shunt creation and variceal coil or plug embolization ineffectively attain gastric variceal decompression or occlusion: results of a 26-patient retrospective study. J Vasc Interv Radiol 2016;27(07):1001-1011

24 Fidelman N, Kwan SW, LaBerge JM, Gordon RL, Ring EJ, Kerlan RK Jr. The transjugular intrahepatic portosystemic shunt: an update. AJR Am J Roentgenol 2012;199(04):746-755 
25 Rosen D, Chu J, Patel R, Moon J, Iyer K, Arnon R. Balloon-occluded retrograde transvenous obliteration for recurrent fundal gastric variceal bleeding in an adolescent. Pediatr Transplant 2014;18 (06):E193-E196

26 Hisamatsu C, Kawasaki R, Yasufuku M, Maeda K. Efficacy and safety of balloon-occluded retrograde transvenous obliteration for gastric fundal varices in children. Pediatr Surg Int 2008;24 (10):1141-1144

27 Nagata H, Yamamura K, Ikeda K, Ihara K, Hara T. Balloon-occluded retrograde transvenous obliteration for congenital portosystemic venous shunt: report of two cases. Pediatr Int 2012;54(03):419-421

28 Hwang J-B, Jung EY, Park W-H, Kim YH, Kim AS. Balloon-occluded retrograde transvenous obliteration treats hepatic dysfunction and gastric varices. J Pediatr Gastroenterol Nutr 2011;52(02):219-221

29 Sasaki T, Hasegawa T, Kimura T, et al. Balloon-occluded retrograde transvenous obliteration performed in a pediatric patient with isolated gastric fundal varices. Journal of Pediatric Surgery 2004; 39(01):130-132

30 Saad WEA, Anderson CL, Patel RS, et al. Management of gastric varices in the pediatric population with balloon-occluded retrograde transvenous obliteration (BRTO) utilizing sodium tetradecyl sulfate foam sclerosis with or without partial splenic artery embolization. Cardiovasc Intervent Radiol 2015;38(01):236-241

31 Shigeta T, Kasahara M, Sakamoto S, et al. Balloon-occluded retrograde transvenous obliteration for a portosystemic shunt after pediatric living-donor liver transplantation. Journal of Pediatric Surgery 2011;46(06):e19-e22

32 Hayashi S, Saeki S, Ushini T. Gastric fundic varices: hemodynamics and non-surgical treatment. Dig Endosc 2005;17(03):198-202

33 Takahashi T, Yoshida H, Mamada Y, Taniai N, Tajiri T. Balloonoccluded retrograde transvenous obliteration for gastric varices in a child with extrahepatic portal venous obstruction. J Nippon Med Sch 2009;76(03):173-178

34 Kiyosue H, Tanoue S, Kondo Y, et al. Balloon-occluded retrograde transvenous obliteration of complex gastric varices assisted by temporary balloon occlusion of the splenic artery. J Vasc Interv Radiol 2011;22(07):1045-1048

35 Yoshimatsu R, Yamagami T, Tanaka O, Miura H, Hashiba M. Hemodynamic changes after balloon occlusion of the splenic artery during balloon-occluded retrograde transvenous obliteration for gastric varices. J Vasc Interv Radiol 2012;23(09): 1207-1212

36 Wada H, Hashizume M, Yamaga H, Kitano S, Sugimachi K. Hemodynamic and morphological changes in the dog kidney after injection of $5 \%$ ethanolamine oleate into the superior vena cava. Eur Surg Res 1990;22(02):63-70

37 Deuel JW, Schaer CA, Boretti FS, et al. Hemoglobinuria-related acute kidney injury is driven by intrarenal oxidative reactions triggering a heme toxicity response. Cell Death Dis 2016;7(01): e2064

38 Imai Y, Nakazawa M, Ando S, Sugawara K, Mochida S. Long-term outcome of 154 patients receiving balloon-occluded retrograde transvenous obliteration for gastric fundal varices. J Gastroenterol Hepatol 2016;31(11):1844-1850

39 Saad WEA. The history and evolution of balloon-occluded retrograde transvenous obliteration (brto): from the United States to Japan and back. Semin Intervent Radiol 2011;28(03):283-287

40 Satapathy SK, Sanyal AJ. Nonendoscopic management strategies for acute esophagogastric variceal bleeding. Gastroenterol Clin North Am 2014;43(04):819-833

41 Kumamoto $\mathrm{M}$, Toyonaga $\mathrm{A}$, Inoue $\mathrm{H}$, et al. Long-term results of balloon-occluded retrograde transvenous obliteration for gastric fundal varices: hepatic deterioration links to portosystemic shunt syndrome. J Gastroenterol Hepatol 2010;25(06):1129-1135

42 Shimoda R, Horiuchi K, Hagiwara S, et al. Short-term complications of retrograde transvenous obliteration of gastric varices in patients with portal hypertension: effects of obliteration of major portosystemic shunts. Abdom Imaging 2005;30(03):306-313
43 Saad WE, Chick JFB, Srinivasa RN, et al. Two-year outcomes of balloon-occluded retrograde transvenous obliteration of gastric varices in liver transplant recipients: a multi-institutional study. Diagn Interv Imaging 2017;98(11):801-808

44 Heaton ND, Davenport M, Howard ER. Incidence of haemorrhoids and anorectal varices in children with portal hypertension. $\mathrm{Br} \mathrm{J}$ Surg 1993;80(05):616-618

45 Hosking SW, Smart HL, Johnson AG, Triger DR. Anorectal varices, haemorrhoids, and portal hypertension. Lancet 1989;1(8634): 349-352

46 Shudo R, Yazaki Y, Sakurai S, Uenishi H, Yamada H, Sugawara K. Clinical study comparing bleeding and nonbleeding rectal varices. Endoscopy 2002;34(03):189-194

47 Robertson M, Thompson AI, Hayes PC. The Management of bleeding from anorectal varices. Curr Hepatol Rep 2017;16(04): 406-415

48 Kimura T, Haruta I, Isobe Y, et al. A novel therapeutic approach for rectal varices: a case report of rectal varices treated with double balloon-occluded embolotherapy. Am J Gastroenterol 1997;92 (05):883-886

49 Okazaki H, Higuchi K, Shiba M, et al. Successful treatment of giant rectal varices by modified percutaneous transhepatic obliteration with sclerosant: report of a case. World J Gastroenterol 2006;12 (33):5408-5411

50 Watanabe $\mathrm{K}$, Imai $\mathrm{Y}$, Takaya $\mathrm{H}$, et al. A case of liver cirrhosis due to hepatits $C$ virus infection complicating giant anorectal varices treated with balloon-occluded retrograde transvenous obliteration. Clin J Gastroenterol 2011;4(01):19-23

51 Minamiguchi H, Kawai N, Sato M, et al. Successful treatment of endoscopically unmanageable rectal varices by balloon-occluded antegrade transvenous sclerotherapy followed by microcoil embolization. J Vasc Interv Radiol 2013;24(09):1399-1403

52 Shin DS, Kim AG, Ingraham CR. Balloon-occluded antegrade transvenous obliteration via transjugular intrahepatic access for bleeding rectal varices. Radiol Case Rep 2019;14(07):805-808

53 Ibukuro K, Kojima K, Kigawa I, et al. Embolization of rectal varices via a paraumbilical vein with an abdominal wall approach in a patient with massive ascites. J Vasc Interv Radiol 2009;20(09):1259-1261

54 Arai H, Kobayashi T, Takizawa D, Toyoda M, Takayama H, Abe T. Transileocolic vein obliteration for bleeding rectal varices with portal thrombus. Case Rep Gastroenterol 2013;7(01):75-81

55 Abdel-Aal AK, Dawoud N, Moustafa AS, Hamed MF, Saddekni S. Percutaneous transhepatic embolization of bleeding rectal varices using a new embolic and sclerotic mixture augmented by Amplatzer Vascular Plug 2. J Radiol Case Rep 2016;10(09):44-51

56 Ohta M, Hashizume M, Kawanaka $\mathrm{H}$, et al. Complications of percutaneous transhepatic catheterization of the portal venous system in patients with portal hypertension. J Gastroenterol Hepatol 1996;11(07):630-634

57 Chu J, Kerkar N, Miloh TA, et al. Roux-en-Y loop varices in children with portal hypertension after liver transplantation: an unusual cause of "obscure" gastrointestinal bleeding. Pediatr Transplant 2011;15(08):E156-E161

58 Bass LM, Kim S, Superina R, Mohammad S. Jejunal varices diagnosed by capsule endoscopy in patients with post-liver transplant portal hypertension. Pediatr Transplant 2017;21(01):e12818

59 Sasamoto A, Kamiya J, Nimura Y, Nagino M. Successful embolization therapy for bleeding from jejunal varices after choledochojejunostomy: report of a case. Surg Today 2010;40(08):788-791

60 Norton ID, Andrews JC, Kamath PS. Management of ectopic varices. Hepatology 1998;28(04):1154-1158

61 Watanabe N, Toyonaga A, Kojima S, et al. Current status of ectopic varices in Japan: Results of a survey by the Japan Society for Portal Hypertension. Hepatol Res 2010;40(08):763-776

62 Sonomura T, Horihata K, Yamahara K, et al. Ruptured duodenal varices successfully treated with balloon-occluded retrograde transvenous obliteration: usefulness of microcatheters. AJR Am J Roentgenol 2003;181(03):725-727 
63 Saad WEA, Lippert A, Saad NE, Caldwell S. Ectopic varices: anatomical classification, hemodynamic classification, and hemodynamic-based management. Tech Vasc Interv Radiol 2013;16 (02):158-175

64 Tominaga K, Montani A, Kuga T, et al. Combined balloon-occluded embolization for treatment of concurrent duodenal, gastric, and esophageal varices: a case report. Gastrointestinal Endoscopy 2001;53(06):665-668

65 Linder S, Wiechel KL. Duodenal varicose veins. Surg Endosc 1991; 5(01):31-35

66 Kochar N, Tripathi D, McAvoy NC, Ireland H, Redhead DN, Hayes PC. Bleeding ectopic varices in cirrhosis: the role of transjugular intrahepatic portosystemic stent shunts. Aliment Pharmacol Ther 2008;28(03):294-303

67 Zamora CA, Sugimoto K, Tsurusaki M, et al. Endovascular obliteration of bleeding duodenal varices in patients with liver cirrhosis. Eur Radiol 2006;16(01):73-79

68 Saad WE, Lippert A, Schwaner S, Al-Osaimi A, Sabri S, Saad N. Management of bleeding duodenal varices with combined tips decompression and trans-TIPS transvenous obliteration utilizing $3 \%$ sodium tetradecyl sulfate foam sclerosis. J Clin Imaging Sci 2014;4:67

69 Chick JFB, Jo A, Dasika N, Saad WE, Srinivasa RN. Transsplenic endovascular recanalization and stenting of a completely occluded portal vein with jejunal variceal embolization in a pediatric liver transplant recipient. Pediatr Radiol 2017;47(08):1012-1015

70 Pimpalwar S, Chinnadurai P, Hernandez A, Kukreja K, Siddiqui S, Justino $\mathrm{H}$. Trans-splenic access for portal venous interventions in children: do benefits outweigh risks? Cardiovasc Intervent Radiol 2018;41(01):87-95

71 Yoshimatsu R, Yamagami T, Ishikawa M, et al. Embolization therapy for bleeding from jejunal loop varices due to extrahepatic portal vein obstruction. Min Invas Ther \& Allied Techno 2016;25 (01):57-61

72 Sato T, Yasui O, Kurokawa T, Hashimoto M, Asanuma Y, Koyama K. Jejunal varix with extrahepatic portal obstruction treated by embolization using interventional radiology: report of a case. Surg Today 2003;33(02):131-134

73 Saeki Y, Ide K, Kakizawa H, Ishikawa M, Tashiro H, Ohdan H. Controlling the bleeding of jejunal varices formed at the site of choledochojejunostomy: report of 2 cases and a review of the literature. Surg Today 2013;43(05):550-555

74 Shim DJ, Shin JH, Ko G-Y, et al. Portal vein stent placement with or without varix embolization of jejunal variceal bleeding after hepatopancreatobiliary surgery. Acta Radiol 2017;58(04):423-429

75 Choi JW, Kim H-C, Jae HJ, et al. Transcatheter embolotherapy with $\mathrm{N}$-butyl cyanoacrylate for ectopic varices. Cardiovasc Intervent Radiol 2015;38(02):344-351

76 Read AJ, Appelman HD, DiMagno MJ. Massive jejunal bleeding from an unlikely source. Clin Gastroenterol Hepatol 2016;14(02): A25-A26

77 Wiesner RH, LaRusso NF, Dozois RR, Beaver SJ. Peristomal varices after proctocolectomy in patients with primary sclerosing cholangitis. Gastroenterology 1986;90(02):316-322

78 Kabeer MA, Jackson L, Widdison AL, Maskell G, Mathew J. Stomal varices: a rare cause of stomal hemorrhage. A report of three cases. Ostomy Wound Manage 2007;53(08):20-22, 24, 26 passim
79 Saad WE, Saad NE, Koizumi J. Stomal varices: management with decompression tips and transvenous obliteration or sclerosis. Tech Vasc Interv Radiol 2013;16(02):176-184

80 Arulraj R, Mangat KS, Tripathi D. Embolization of bleeding stomal varices by direct percutaneous approach. Cardiovasc Intervent Radiol 2011;34(Suppl 2):S210-S213

81 Yao D-H, Luo X-F, Zhou B, Li X. Ileal conduit stomal variceal bleeding managed by endovascular embolization. World J Gastroenterol 2013;19(44):8156-8159

82 Sengodan P, Anna K, Reed S, Shah B, Jain A, Kyprianou A. A case of recurrent bleeding stomal varix controlled using embolization with a liquid copolymer: an effective therapy for palliation. J Palliat Med 2014;17(01):85-87

83 Samaraweera RN, Feldman L, Widrich WC, et al. Stomal varices: percutaneous transhepatic embolization. Radiology 1989;170(3 Pt 1):779-782

84 Thouveny F, Aubé C, Konaté A, Lebigot J, Bouvier A, Oberti F. Direct percutaneous approach for endoluminal glue embolization of stomal varices. J Vasc Interv Radiol 2008;19(05): 774-777

85 Sabri SS, Swee W, Turba UC, et al. Bleeding gastric varices obliteration with balloon-occluded retrograde transvenous obliteration using sodium tetradecyl sulfate foam. J Vasc Interv Radiol 2011;22(03):309-316, quiz 316

86 Hiraga N, Aikata H, Takaki S, et al. The long-term outcome of patients with bleeding gastric varices after balloon-occluded retrograde transvenous obliteration. J Gastroenterol 2007;42 (08):663-672

87 Fukuda T, Hirota S, Sugimura K. Long-term results of balloonoccluded retrograde transvenous obliteration for the treatment of gastric varices and hepatic encephalopathy. J Vasc Interv Radiol 2001;12(03):327-336

88 Sauer BG, Sabri SS, Shami VM, Al-Osaimi AMS. Balloon-occluded retrograde transvenous obliteration (BRTO): follow-up and postprocedural imaging. Semin Intervent Radiol 2011;28(03): 325-332

89 Wang AJ, Li BM, Zheng XL, Shu X, Zhu X. Utility of endoscopic ultrasound in the diagnosis and management of esophagogastric varices. Endosc Ultrasound 2016;5(04):218-224

90 Saraireh HA, Bilal M, Singh S. Role of endoscopic ultrasound in liver disease: where do we stand in 2017? World J Hepatol 2017;9 (24):1013-1021

91 El-Shabrawi M, El-Shabrawi MHF, Isa M, Kamal NM. Management of portal hypertension in children: a focus on variceal bleeding. J Gastroenterol Hepatol Res 2012;1(02):20-26

92 Vogel CB. Pediatric portal hypertension: A review for primary care. Nurse Pract 2017;42(05):35-42

93 Giouleme O, Theocharidou E. Management of portal hypertension in children with portal vein thrombosis. J Pediatr Gastroenterol Nutr 2013;57(04):419-425

94 Kirby JM, Cho KJ, Midia M. Image-guided intervention in management of complications of portal hypertension: more than TIPS for success. Radiographics 2013;33(05):1473-1496

95 Sarin SK, Lahoti D, Saxena SP, Murthy NS, Makwana UK. Prevalence, classification and natural history of gastric varices: a long-term follow-up study in 568 portal hypertension patients. Hepatology 1992;16(06):1343-1349 